\title{
Laparoendoscopic single-site transvesical removal of mid-urethral polypropylene sling eroded into the bladder
}

\author{
Marek Roslan, Marcin Markuszewski, Artur Gibas, Wojciech Piaskowski, Kazimierz Krajka \\ Department of Urology, Medical University of Gdansk, Poland
}

Videosurgery and other miniinvasive techniques 2011; 6 (2): 111-114 DOI: $10.5114 /$ wiitm.2011.23221

\begin{abstract}
Complications of mid-urethral sling procedure such as erosion into the bladder are not very common. However, when they occur, removal of the tape may be necessary. To date, this complication has usually been managed by retropubic exploration or operative cystoscopy, which can often be associated with disproportionate morbidity or even failure. We present 2 cases of a laparoendoscopic single-site surgery (LESS) approach for removal of polypropylene tape eroded into the bladder. We report two female patients aged 41 years and 47 years who underwent treatment with this novel technique. A TriPort ${ }^{\circledR}$ single-site access system was placed through the apex of the bladder under cystoscopic control. Carbon dioxide was used for insufflations of the bladder. A combination of straight and articulating laparoscopic instruments was used to dissect and completely remove the foreign body. Both patients were managed adequately in the manner presented above. The length of the skin incision was $20 \mathrm{~mm}$. Time of intervention was $35 \mathrm{~min}$ and $40 \mathrm{~min}$. No blood loss or complications occurred. A Foley $18 \mathrm{~F}$ catheter was left for seven days and the patients were discharged on the $1^{\text {st }}$ postoperative day. The follow-up period (4 months and 7 months) showed no events related to the method. Removal of foreign bodies of the bladder through a single transvesical laparoscopic port is technically feasible. This procedure offers excellent visualization inside the bladder, especially near the bladder neck where polypropylene tapes often reside, and provides patients with a minimally invasive approach through a single small incision.
\end{abstract}

Key words: incontinence, mid-urethral sling, tape erosion, laparoendoscopic single-site surgery.

\section{Introduction}

Mid-urethral polypropylene slings have become a standard treatment of stress urinary incontinence (SUI) in women for the last two decades. Retropubic tension-free vaginal tape (TVT) is the most common anti-incontinence procedure and over one million TVT slings have been placed worldwide since 1996 [1]. The number of complications reported in the retropubic route ranges from $4.3 \%$ to $75.1 \%$ [2]. Erosions of the tape into genitourinary organs are rare events and occur in $0.3 \%$ to $14 \%$ of cases $[3,4]$. The most common symptoms related to this complication are recurrent urinary tract infection (UTI) and chronic pelvic pain [4]. To date, tapes are usually removed using several different techniques, such as open cystotomy, operative cystoscopy, transurethral resection or laparoscopy [4-7]. An open approach is associated with a comparatively large trauma but endoscopic surgery is inconvenient and often inefficient. The laparoscopic approach is minimally invasive and efficient but it is associated with a small risk of bowel injury. Nevertheless, laparoscopy has been demonstrated as a valid approach in a variety of surgical procedures with better results in terms of perioperative morbidity, shorter hospital stay and consequent improved quality of life [7]. Recently, some efforts have been made to decrease morbidity related to 
laparoscopic port placement and improve cosmetic results while maintaining the same standards of surgical care. In this context, mini-laparoscopic approaches such as laparoendoscopic single-site surgery (LESS), single-port incision laparoscopic surgery (SILS) and natural orifice translumenal endoscopic surgery (NOTES) have been developed [8, 9]. Until now single-port techniques have been applied to perform a wide range of surgical, urological and gynecologic interventions, from hernia repair to cancer resections and even live donor nephrectomies [10-13].

Laparoendoscopic single-site surgery reduces the number of ports necessary to complete laparoscopic surgery and might reduce intraoperative complications and postoperative morbidity. In the current study, we describe our specific clinical experience of managing bladder erosion of mid-urethral tape using this novel and challenging technique.

This study presents our experience with the LESS procedure for removal of polypropylene tape eroded into the bladder.

\section{Case report}

From November 2009 to February 2010 two female patients aged 41 years and 57 years were referred to our hospital with urgency, pelvic pain and recurrent UTI. Symptoms were refractory to medical treatment, including anaesthetics, antimuscarinic agents and antibiotics. Respectively 15 and 8 months before admission they underwent surgery for SUI with the use of suprapubic polypropylene tape. In the first case the tape was cut out from polypropylene hernia mesh (GYNECARE GYNEMESH ${ }^{\circledR}$ PS, Ethicon Women's Health \& Urology, Somerville, NJ, USA). In the latter one the original tape (Gal-Mesh, Gallini Medical Devices, Mantova, Italy) was placed with the set of self-adapted instruments.

Bacteriological analysis revealed Escherichia coli in both cases. Cystoscopy was conducted as well as vaginal examination to look specifically for evidence of bladder erosion, vesico-vaginal fistula, granulation tissue and any scarring of the anterior vaginal wall. In both patients the assessment showed the presence of 2-3 cm long erosion of the tape laterally (on the left) to the bladder neck. No fistula was found. Women were qualified for laparoendoscopic singlesite removal of the tape.

Patients were placed in the lithotomy position and subjected to general anaesthesia. Surgical proce- dures were performed through a single multiport trocar TriPort ${ }^{\circledR}$ (Olympus Winter \& IBE GMBH, Hamburg, Germany), inserted directly into the bladder through a $2 \mathrm{~cm}$ longitudinal skin incision located $2 \mathrm{~cm}$ above the pubic symphysis. Before trocar insertion the bladder was filled with $500 \mathrm{ml}$ of $0.9 \%$ saline. Cystoscopic control was necessary. Carbon dioxide was used for insufflation of the bladder and the $10 \mathrm{~mm} 30^{\circ}$ laparoscopic optic was introduced into the bladder. The eroded tape was located, dissected and removed using a combination of straight and articulating laparoscopic instruments. Fragments of tapes were sent for bacteriological examination. Electrocautery was sufficient to stop the small bleeding. There was no need to close the bladder wall with a suture, either inside the bladder or in the apex after removal of the TriPort trocar. After the procedure an $18 \mathrm{~F}$ Foley catheter was established intravesically. The skin incision was closed with two sutures.

The follow-up was scheduled at 1, 3 and 6 months after surgery and continence, pain, voiding difficulties and culture were reassessed. The recurrence of SUI was evaluated by clinical examination and 24hour pad test.

Both patients were managed adequately in the manner presented above. The length of the skin incision was $20 \mathrm{~mm}$. No extra port was introduced. Time of intervention was $35 \mathrm{~min}$ and 40 min respectively. No blood loss or complication occurred. A Foley $18 \mathrm{~F}$ catheter was left for seven days and patients were discharged on the $1^{\text {st }}$ postoperative day. Cultures of removed tapes were negative.

All women reported a complete decrease of pain and no urgency after one month of follow-up. Recurrent stress urinary incontinence occurred in both females. On the basis of the patient's opinion (no pad tests obtained before initial treatment), the grade of urine leakage was less than before the sling procedure. 24-hour pad test was $8 \mathrm{~g}$ and $25 \mathrm{~g}$ respectively and the patients declined re-treatment. At the followup time of 9 months and 6 months respectively no adverse events related to the method appeared. Bacteriological urine assessment was negative in both cases.

\section{Discussion}

The suprapubic tension-free vaginal tape for female stress urinary incontinence (SUI) was introduced in 1995 by Ulmsten and Petros [14]. In the subsequent years several other pubovaginal or transob- 
turator polypropylene sling systems have been developed and have quickly gained worldwide acceptance due to good functional results and low complication rates [15]. Erosion of sling materials into the lower urinary tract is an uncommon but known complication after pubovaginal sling placement. Urethral erosion is reported at a rate from $2.7 \%$ to $33 \%$ and bladder erosion is much less common with incidences ranging from $0.5 \%$ to $0.6 \%$, but these data are obtained mainly from the literature on TVT or other well-described techniques [3, 16-18]. There are no reliable analyses of so-called "hand-made" tapes although this kind of procedure is likely performed in many countries.

The data obtained from the centre referring the above-mentioned patients were insufficient. We have been informed that in this centre only 15 to 20 incontinent women were operated on yearly. The surgeons used to perform the hand-made system only. This material is not numerous but it is justified to estimate that the bladder erosion rate in that centre is unacceptably high and probably ranges around 5-10\%. Two new such cases referred to our centre just after we summed up the first pair confirm this estimation.

Tape erosion into the bladder necessitates its removal, and laparotomy and operative cystoscopy have been described as applicable methods [5, 17]. Laparoscopy has been shown to be a safe and efficient procedure as well as other techniques [7, 19-21]. The advantages of laparoscopic access are improved visualization, less postoperative pain, shorter hospital stay, and faster recovery time. Nevertheless, it requires the placement of 3 or more trocars, each creating its own incision [7, 19]. The endoscopic procedures seem to be simpler but the inconvenience in using manipulators often leads to prolonged intervention time or even failure [18, 20].

Consequently the mini-laparoscopic approaches such as LESS or SILS have been considered as possible ways for removal of bladder foreign bodies.

There are only a few reports on the use of singleport access for tape removal directly from the bladder $[21,22]$. The experiences are encouraging even for outpatient surgery [21]. The TriPort $^{\circledR}$ allows up to 3 instruments to be used simultaneously through a single incision and makes single-port surgery feasible and efficient. This port is sharply ended and blunt insertion into the bladder does not give rise to any difficulties. The short procedure time of our initial attempts encourages continuation of this method. However, further refinements in instrumentation and operative techniques will be required before this way of surgical access can be widely accepted.

\section{Conclusions}

In this paper we have demonstrated the feasibility and efficacy of the LESS technique for removal of eroded slings from the bladder. This procedure offers excellent visualization inside the bladder and provides patients with a minimally invasive approach through a single small incision. Introduction of articulating instruments, multifunctional devices and a flexible 5-mm camera can overcome the limitations of a reduced number of ports.

\section{References}

1. Latthe PM, Foon R, Toozs-Hobson P. Transobturator and retropubic tape procedures in stress urinary incontinence: a systematic review and meta-analysis of effectiveness and complications. BJOG 2007; 114: 522-31.

2. Daneshgari F, Kong W, Swartz M. Complications of mid urethral slings: important outcomes for future clinical trials. J Urol 2008; 180: 1890-7.

3. Hammad FT, Kennedy-Smith A, Robinson RG. Erosions and urinary retention following polypropylene synthetic sling: Australasian survey. Eur Urol 2005; 47: 641-7.

4. Kobashi K, Dmochowski R, Mee SL, et al. Erosion of woven polyester pubovaginal sling. J Urol 1999; 162: 2070-2.

5. Volkmer BG, Nesslauer T, Rinnab L, et al. Surgical intervention for complications of the tension-free vaginal tape procedure. J Urol 2003; 169: 570-4.

6. Charalambous S, Tountziaris C, Karapanagiotidis C, et al. A simple technique for intravesical tape removal. Pelviperineology 2008; 27: 26-7.

7. Roupret M, Misraï V, Vaessen C, et al. Laparoscopic surgical sling resection for tension-free vaginal tape - related complications refractory to first-line conservative management: a single center experience. Eur Urol 2010; 58: 270-4.

8. Kaouk J, Haber, Goel GR, et al. Single-port laparoscopic surgery in urology: initial experience. Urology 2008; 71: 3-6.

9. Zhu J. Scarless endoscopic surgery: NOTES or TUES. Surg Endosc 2007; 21: 1898-9.

10. Śmietański M, Kitowski J, Tarasiuk D. Laparoscopic abdominal hernia repair with SILS${ }^{\circledR}$ port - our first experiences. Videosurgery and other miniinvasive techniques 2009; 4: 76-8.

11. Michalik M, Orłowski M, Frask A, et al. LESS (laparo-endoscopic single-site surgery) right hemicolectomy. Videosurgery and other miniinvasive techniques 2009; 4: 164-7.

12. Fagotti A, Fanfani F, Rossitto C, et al. Laparoendoscopic singlesite surgery for the treatment of benign adnexal disease: A prospective trial. Diagnostic and Therapeutic Endoscopy 2010; ID 108258. 
13. Ganpule A, Dhawan D, Kurien A, et al. Laparoendoscopic singlesite donor nephrectomy: a single-center experience. Urology 2009; 74: 1238-40.

14. Ulmsten U, Petros P. Intravaginal sling (IVS): an ambulatory surgical procedure for treatment of female urinary incontinence. Scand J Urol Nephrol 1995; 29: 75-82.

15. Rapp DE, Kobashi KC. The evolution of midurethral slings. Nat Clin Pract Urol 2008; 5: 194-201

16. Costantini E, Lazzeri M, Porena M. Managing complications after midurethral slings for stress urinary incontinence. EAU-EBU Update Series 2007; 5: 232-40.

17. Levin I, Groutz A, Gold R, et al. Surgical complications and medium-term outcome results of tension-free vaginal tape: a prospective study of 313 consecutive patients. Neurourol Urodyn 2004; 23: 7-9

18. Foley C, Patki P, Boustead B. Unrecognized bladder perforation with mid-urethral slings. www3.BJU international 2010; interscience.wiley.com/journal/123476589/abstract.

19. Pikaart D, Miklos J, Moore RD. Laparoscopic removal of pubovaginal polypropylene tension-free tape slings. JSLS 2006; 10: 220-5.

20. Feiner B, Auslender R, Mecz Y, et al. Removal of an eroded transobturator tape from the bladder using laser cystolithotripsy and cystoscopic resection. Urology 2009; 73: 681.

21. Ingber M, Stein R, Rackley R, et al. Single-port transvesical excision of foreign body in the bladder. Urology 2009; 74: 1347-50.

22. Roslan M, Markuszewski M, Gibas A: Trudna, ale obiecująca wrażenia po wykonaniu pierwszych operacji techniką LESS. Przegl Urolog 2010; 1: 30-1. 